\title{
Postpartum preeclampsia in Bhutan: A case report
}

\author{
Thinley Dorji ${ }^{1}$, Karma Wangmo ${ }^{2}$, and Mamta Subba ${ }^{3}$ \\ ${ }^{1}$ Ministry of Health, Bhutan \\ ${ }^{2}$ Affiliation not available \\ ${ }^{3}$ Ministry of Health
}

October 8, 2020

\begin{abstract}
Pre-eclampsia usually occurs in the antenatal period after 20 weeks of gestation. However, case of postpartum preeclampsia can also occur especially within the first one week after the delivery. The diagnosis of postpartum preeclampsia can be easily missed since it is rare.
\end{abstract}

\section{Key words}

Preeclampsia, Bhutan, hypertension in pregnancy, eclampsia

\section{Key Clinical Message}

Postpartum preeclampsia can sometimes occur after the birth of the baby within six weeks postpartum. Unless close monitoring is done in postpartum mothers, it can be easily missed. Therefore, postnatal checkup should be closely followed.

\section{Introduction}

Hypertensive disorder in pregnancy is a common cause of maternal morbidity and mortality. It is known to occur in 6 to $8 \%$ of all pregnancies (1) especially in the developing countries (2). According to National High Blood Pressure Education Program Working Group Report on High Blood Pressure in Pregnancy, the hypertension in pregnancy is divided into chronic hypertension, preeclampsia superimposed on chronic hypertension, preeclampsia-eclampsia, gestational hypertension (1). If untreated, they can lead to maternal complications like eclampsia, placental abruption, postpartum hemorrhage, disseminated intravascular coagulation, renal failure, cerebral oedema and HELLP syndrome (Hemolysis, elevated liver enzymes and low platelets) $(1,3,4)$. The common fetal complications include intrauterine growth retardation, preterm delivery and intrauterine deaths (3).

Preeclampsia is defined as presence of BP $>140 / 90$ along with proteinuria after 20 weeks of pregnancy on two or more occasions four hours apart. It is the most common form of hypertensive disorder in pregnancy (5). Although, it is commonly reported during the time of pregnancy, sometimes it can be reported as late as 4-6 weeks after the delivery (5) where it is defined as postpartum preeclampsia. However, it commonly occurs within the first seven days after delivery of the baby due to absorption of extracellular fluid into the vessels (6). Presently, there are few studies on postpartum preeclampsia. A study in US showed the incidence of postpartum preeclampsia to be $5.7 \%$ (7). The diagnosis of postpartum preeclampsia can be missed due to our focus mainly on antenatal and intrapartum care. Here, we present a case of mother who developed postpartum preeclampsia in Bhutan.

\section{CASE STUDY}


A previously healthy 31-year primigravida developed weakness of bilateral lower limbs and paresthesia at 36 weeks of pregnancy. Her antenatal period was unremarkable. She was admitted in the hospital and diagnosed to have peripheral neuropathy. On the day of admission, her hemoglobin was $9.8 \mathrm{gm} / \mathrm{dl}$. Her liver function test and renal function test were within normal limits except for hyperchloremia $(115 \mathrm{mEq} / \mathrm{L}$ (Normal; $96-110 \mathrm{mEq} / \mathrm{L}$ ). Her urine albumin and urine glucose using dipstick was nil. She was treated with vitamin B complex tablets along with tablet thiamine $75 \mathrm{mg}$ twice a day. She also received Neurobion injection (Vitamin B complex). She delivered a healthy male baby at $37^{+5}$ weeks of pregnancy. The postpartum period was unremarkable and she was subsequently discharged as case of peripheral neuropathy with vitamin B. complex tablet and thiamine tablet.

On postpartum day 5, she presented with complaints of bilateral leg swelling. On examination, she had weakness of bilateral legs with power of $4 / 5$. She was found to have high blood pressure of 180/120 with pedal oedema $(+++)$. She denied having symptoms of severe headache, shortness of breath or visual disturbances. Her hemoglobin was $10 \mathrm{~g} / \mathrm{dl}$ with normal renal and liver function tests. Her blood platelets were also within the normal limits. The urine analysis showed urine albumin of $2+$. She was started on tablet Losartan $50 \mathrm{mg}$ twice a day, Tablet furosemide $40 \mathrm{mg}$ once a day and Tablet Nifedipine $20 \mathrm{mg}$ once a day. She was treated as a case of postpartum preeclampsia. During the course of her admission, she also received tablet Vitamin B complex, tablet thiamine $75 \mathrm{mg}$ bd and injection Cyanocobalamin $1 \mathrm{mg}$ od.

Her blood pressure decreased on day 4 of admission and her urine albumin also became negative. Her symptoms subsided and she was subsequently discharged.

\section{Discussion}

The most common cause of postpartum preeclampsia is presence of gestational hypertension or preeclampsia during the pregnancy. Other causes include volume overload with intravenous fluids at the time of delivery, non-steroidal anti-inflammatory drugs for pain leading to water retention and use of uterine atony drugs like ergotamine (8). Therefore, injudicious use of these drugs should be prevented.

Preeclampsia can occur in the postpartum period with one-third of them developing eclampsia especially 48 hours after the delivery (9). Untreated postpartum preeclampsia, can lead to eclampsia, intracranial hemorrhage and reversible cerebral vasoconstriction syndrome (8). The management of postpartum preeclampsia includes avoidance of non-steroidal anti-inflammatory drugs and use of selected anti-hypertensives like calcium channel blockers (8) and furosemide (10).

\section{Conclusion}

The postpartum preeclampsia is usually uncommon. Due to this, there are high chances of missing out the diagnosis during the postnatal period. This requires close monitoring of mothers especially among high risk like previous history of preeclampsia, maternal disease like kidney disease, autoimmune diseases, diabetes, high body mass index and advanced maternal age $(11,12)$.

\section{Acknowledgement}

We are grateful to the staff of the Kanglung hospital.

\section{Conflict of interest}

There are no conflicts of interest to declare.

\section{Authors contribution}

TD: initiated the preparation of the manuscript.

KW: Was involved in the writing and finalization of the manuscript.

MS: Was involved in the writing and finalization of the manuscript.

\section{Informed Consent}


A written and verbal consent was obtained from the patient for this case report.

\section{References}

1. Program NHBPE. Report of the national high blood pressure education program working group on high blood pressure in pregnancy. American journal of obstetrics and gynecology. 2000;183(1):s1-s22.

2. Goldenberg RL, McClure EM, Macguire ER, Kamath BD, Jobe AH. Lessons for low-income regions following the reduction in hypertension-related maternal mortality in high-income countries. International journal of gynaecology and obstetrics: the official organ of the International Federation of Gynaecology and Obstetrics. 2011;113(2):91-5.

3. Nisa SU, Shaikh AA, Kumar R. Maternal and Fetal Outcomes of Pregnancy-related Hypertensive Disorders in a Tertiary Care Hospital in Sukkur, Pakistan. Cureus. 2019;11(8).

4. Mustafa R, Ahmed S, Gupta A, Venuto RC. A comprehensive review of hypertension in pregnancy. Journal of pregnancy. 2012;2012.

5. Lim K-H. https://emedicine.medscape.com/article/1476919-overview medscape2018 [Available from: https://emedicine.medscape.com/article/1476919-overview.

6. Firoz T, Sotunsa J, Adetoro OO. Treatment postpartum-immediate and long term. The FIGO Textbook of Pregnancy Hypertension: an Evidence-Based Guide to Monitoring, Prevention and Management London: Global Library of Women's Medicine. 2016:215-32.

7. Matthys LA, Coppage KH, Lambers DS, Barton JR, Sibai BM. Delayed postpartum preeclampsia: an experience of 151 cases. American journal of obstetrics and gynecology. 2004;190(5):1464-6.

8. Bramham K, Nelson-Piercy C, Brown MJ, Chappell LC. Postpartum management of hypertension. Bmj. $2013 ; 346$.

9. Chames MC, Livingston JC, Ivester TS, Barton JR, Sibai BM. Late postpartum eclampsia: a preventable disease? American journal of obstetrics and gynecology. 2002;186(6):1174-7.

10. Veena P, Perivela L, Raghavan SS. Furosemide in postpartum management of severe preeclampsia: A randomized controlled trial. Hypertension in Pregnancy. 2017;36(1):84-9.

11. Quan LM, Xu QL, Zhang GQ, Wu LL, Xu H. An analysis of the risk factors of preeclampsia and prediction based on combined biochemical indexes. The Kaohsiung journal of medical sciences. 2018;34(2):109-12.

12. Fox R, Kitt J, Leeson P, Aye CYL, Lewandowski AJ. Preeclampsia: Risk Factors, Diagnosis, Management, and the Cardiovascular Impact on the Offspring. Journal of clinical medicine. 2019;8(10). 